\title{
Using a Sensor Network for Energy Optimization of Paper Machine Dryer Sections
}

\author{
By Till Hänisch ${ }^{*}$ \\ Dominik Mai ${ }^{\dagger}$
}

\begin{abstract}
This paper presents a case study with regard to using a low cost low power sensor network to save energy in paper machines. By using wireless sensors for measuring temperature and humidity in the dryer section of a paper machine it is possible to optimize energy consumption by adjusting heating and air flow. Because the sensors need to be battery powered with the data sent almost in real time for monitoring purposes, a low power network technology is needed, in this case ZigBee. A prototype installation with a small number of sensors was set up, running over a period of six weeks. First results show an ad hoc optimization and energy savings of some $80.000 €$ per year for a single machine.
\end{abstract}

\section{Introduction}

The paper industry is one of the most energy intensive businesses. The worldwide paper production is approximately 400 million metric tons per year. The required energy is 700 to $1500 \mathrm{kWh} / \mathrm{t}$ for highly optimized machines in Germany, close to $4000 \mathrm{kWh} / \mathrm{t}$ in the UK. By optimizing production parameters of the final products, energy savings of some $10 \%$ can be realized [Austin, 2011]. This is commonly done in Germany, where energy costs are high [Küchler, 2013]. For further reductions of energy consumption, innovative solutions are required.

$80 \%$ of the energy is used in the dryer section of a paper machine [Ghosh11], so here we can find the largest potential for further savings. A large part of the energy is thermal energy in form of steam. This is the reason why most paper machines have their own power stations. They use the steam for the dryer section and sell the electricity on the market. In this situation, the steam is a byproduct and cost is close to nothing. As a consequence of that, there was not much research done on further savings in this area. This is one reason, why the dryer section is usually not fitted with measuring equipment. A second reason are the unfriendly environmental conditions in this section; temperature is above 80 degrees and humidity is high. In recent times, the focus shifts towards further optimization, because the margins of the paper industry are shrinking and energy costs are rising.

*Professor, Baden Württemberg State University, Germany.

'ZM-Technik GmbH, Germany. 
Traditionally, optimizations are done on the basis of single point measurements. Sensors for parameters like temperature and humidity are installed in an ad hoc way and data is recorded over a period of a few hours. Since these measurements can only capture a snapshot of the relevant parameters, they are used mainly to identify production problems under specific conditions (raw material, paper type, operating speed etc.). With such a measurement, it is not possible to conduct a thorough investigation of the thermal situation under different production conditions. Since the relevant parameters such as required steam mass or required air speed in the dryer, cannot be regulated on a short term basis (at least in current machines) these measurements have to be done for all production conditions and product types. In practice, this means that measurements have to be done over a time interval of several weeks. This is not feasible with conventional technology, since the wiring of the sensors and the instrumentation would have to be implemented in a way that would not disturb the normal operation of the paper machine. Operating the machine, includes the use of high pressure water blasters or chemicals for cleaning the machine. This would be too expensive to be considered realistic. This results in operation of dryer sections with a very large safety margin regarding temperature and humidity. Moving to a more efficient operating area results in large energy savings.

Figure 1. Energy Cost in Relation to the Dew Point Temperature

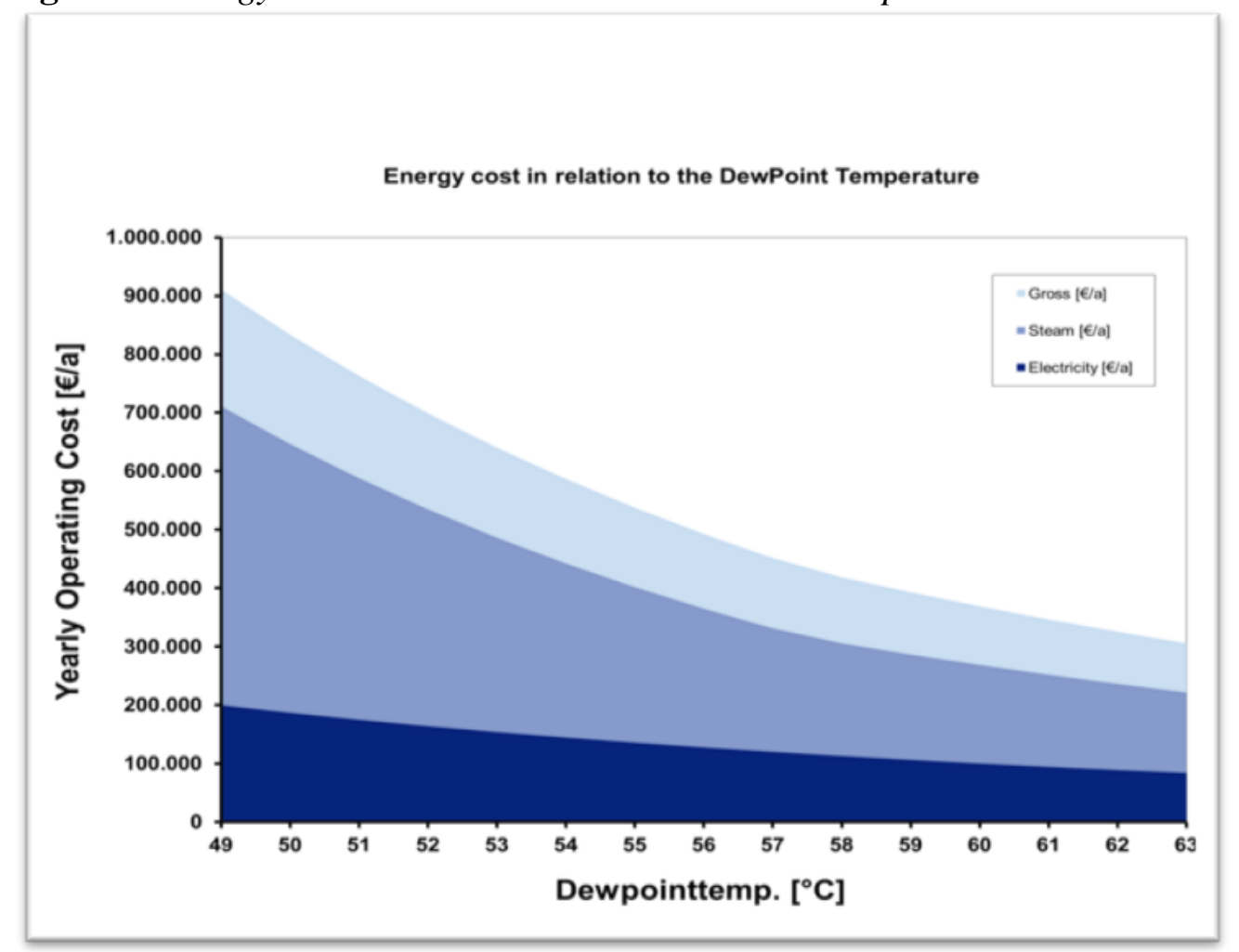

To enable a long term measurement, it is necessary to use economically prized sensors without wiring, which means battery powered and wireless data 
transfer. Using a large number of cost effective sensors connected to the internet can result in drastic optimizations. General Electrics is one of the proponents of this so called Industrial Internet that "could save global industries $\$ 150$ billion annually" [GE: 2012].

One way to optimize energy consumption in the dryer section, is an increase of humidity in the air inside the dryer, as near to the dew point as possible: "The amount of exhaust air should be just enough to carry all of the water vapour out of the dryer, with humidity a little above dew point"[Austin: 2011]. Even a small change in temperature and/or humidity will lead to a massive reduction of energy costs.

\section{Architecture of the System}

To allow a flexible arrangement of the sensor nodes, battery powered sensors have to be used and data has to be transmitted wirelessly. Unfortunately a paper machine consists mainly of metal, and especially the dryer section has a full metal housing. To circumvent possible problems with absorption and reflection of waves, a flexible mesh network topology was used. ZigBee has the necessary flexibility and "most importantly automatic route discovery and self healing" [Gislason, 2008]. If a star topology like WLAN is used, one node of the network (the access point) must be reachable by all other nodes. In a mesh network like ZigBee, data could be routed from node to node. In our first experiments we found that a single routing node is sufficient for the data transmission, but this cannot be considered to be generally the case.

Figure 2. Architecture of the used Sensor Network

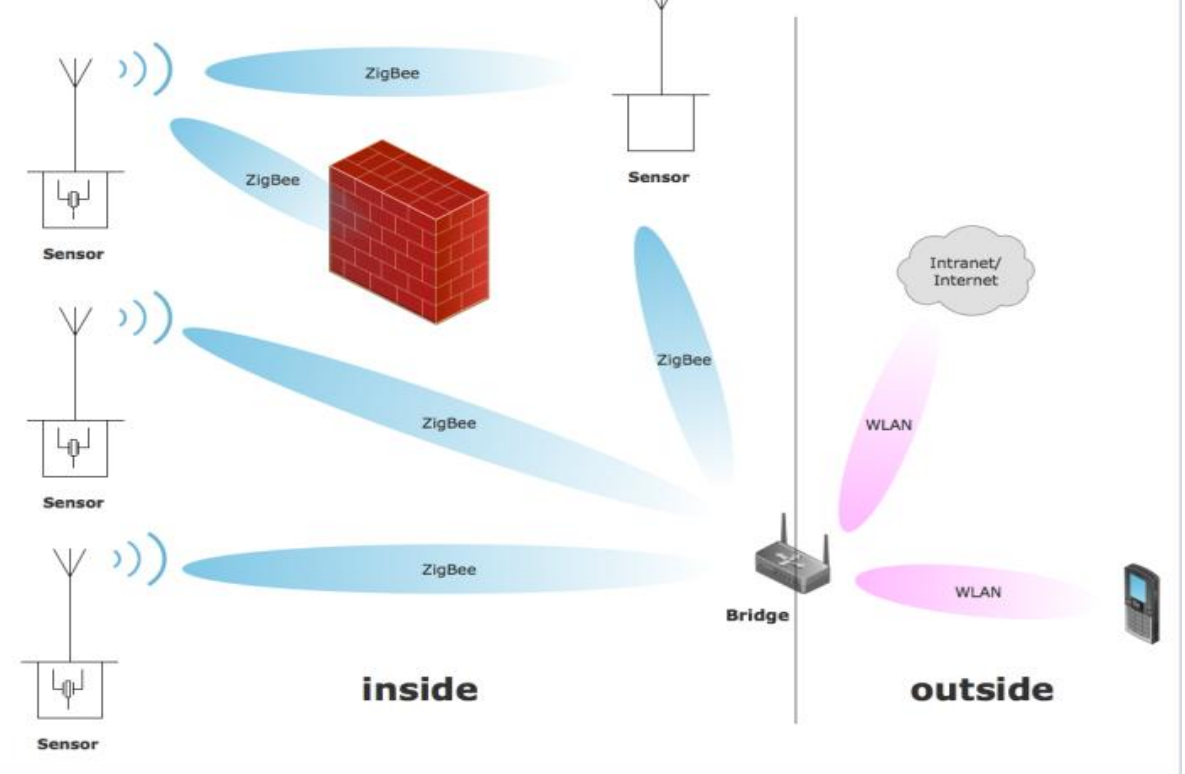


A second (and maybe even larger) advantage of ZigBee compared to WLAN is the lower energy consumption. If a node is powered by a battery, energy is limited. To achieve a long runtime, the nodes are 'sleeping' most of the time and are 'woken up' in regular intervals to measure data. The data is transmitted to other nodes or a gateway as rarely as possible, because the wireless transmission consumes a lot of power (typically around $100 \mathrm{~mW}$ for ZigBee, up to $2 \mathrm{~W}$ for standard WLAN) and this takes a long time. Reading a sensor is usually a matter of a few milliseconds, while data transmissions take much longer, between a few milliseconds for Bluetooth LE up to a large part of a second for WLAN. Even in highly optimized WLAN-systems like the one described in [Ostermeier, 2011], the latency is a few hundred milliseconds.

If data is transmitted only in large time intervals and large batteries can be used this might be acceptable. In our case, battery capacity is reduced by high temperature and costs are a primary factor; therefore, the smaller the batteries, the better.

In our case, the temperature and the humidity of the air around the sensor are measured with Hygrochip HYT939 sensors. Values are measured every four seconds and are transmitted every minute. The sensors are controlled by an Arduino fio controller, because it has a LiPo battery charger and a socket for the digi-XBee module on-board. This results in no special circuit board being required which leads to low manufacturing cost. The sensor has a size of some 100×30×10 mm including battery and a wireless module. This could be reduced even more but is small enough for the required application.

Figure 3. Prototype of a Sensor Node, Sensor is in the Background, Battery (Silver) and Xbee Module are Visible under the Controller Board

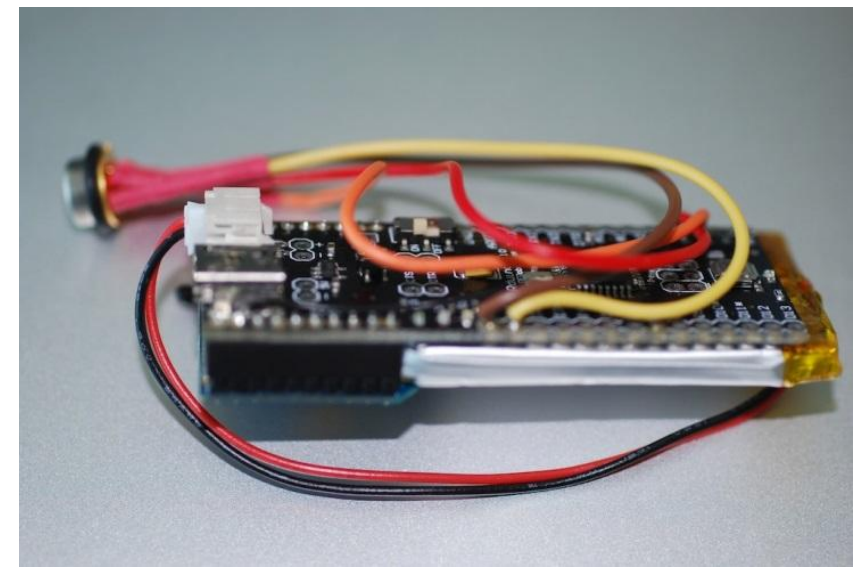

The transmitted data is collected at the bridge, which has a raspberry pi based design that stores all values on a compact flash card and makes them available on the network. Software on the sensor nodes is written in C, software on the bridge in Ruby. 


\section{Results}

Even though our experiments so far were mainly intended to explore the technical properties of the prototype and the feasibility of using this system in paper machines, we already found optimization potentials in the production process.

\section{Production Optimization}

The operations team of the paper machine decided to make an optimization experiment during the test run of the sensors by reducing heating power of the dryer section. It is easy to do that and it is easy to observe the effect of this reduction of the temperature: The humidity goes up (first arrow in figure 4), but doesn't reach critical values (the exact values are not shown, because they are site specific). Measurements like this can easily be done with conventional equipment. But the problem is that a paper machine is operated under different conditions, depending on the paper produced, the raw material etc. So it is necessary to repeat these measurements over a longer period of time. This is shown in figure 4: The reduction of heating power is done at three other times over a time frame of some three weeks. The measured humidity levels at the different positions in the dryer are similar to the first test, but not identical. In none of the critical values reached and this is now the standard operating condition. That alone saves approximately $80.000 €$ per year.

Figure 4. Measured Humidity. The y-axis is the Relative Humidity, the x-axis the Time, approx. 3 weeks in total

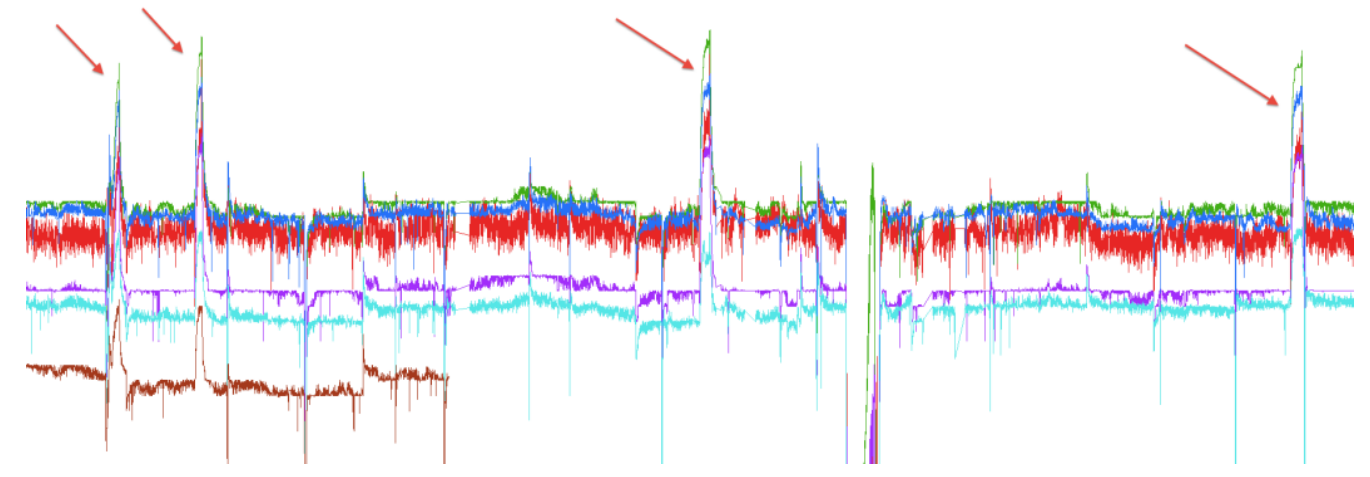

\section{Technical Findings}

We expected that the massive amount of metal in the paper machine would result in massive problems with the wireless data transmission, so it would be essential to use a mesh network with nearly every node being able to route packets. This was not the case. Signal strength measurements inside the dryer showed that most positions in there could be reached directly. The only problem was to get the signal to the outside: The dryer has a complete metal housing to insulate against the much cooler outside world. We solved this problem by using a single router node with a more powerful XBee-Pro module located approximately in the middle of the dryer section. The individual sensor 
nodes sent their data via the router to the bridge located in the control room some 20 meters away from the router. This allowed a simple configuration where the sensor nodes were not synchronized and the (single) router was working continuously. This required a larger battery $(6 \times 2 \mathrm{~B}$ standard cells) for the router but since it was only one router, this was not considered a problem, neither technically nor regarding the cost of the system.

But this leads to a different problem.

When a sensor is not able to reach the router (or the bridge directly) the packet gets retransmitted automatically by the ZigBee stack. This requires additional energy. In figure 6 the interval between two consecutive packets from a sensor is shown. Since the packets are sent every minute this interval should always be close to 60 seconds. This is not always true. The timing from the sensor shown in figure 6 shows that this sensor obviously has problems sending its packets. Often it works, but more often it does not. While it is not critical for the results of the measurements, if some records are lost, this results in a much higher energy consumption, which leads to a failure of this sensor after only about one week. This can also be seen in figure 4 where one sensor (the lowest curve) stops sending data after some time.

Figure 5. Part of the Dryer Section of a Paper Machine

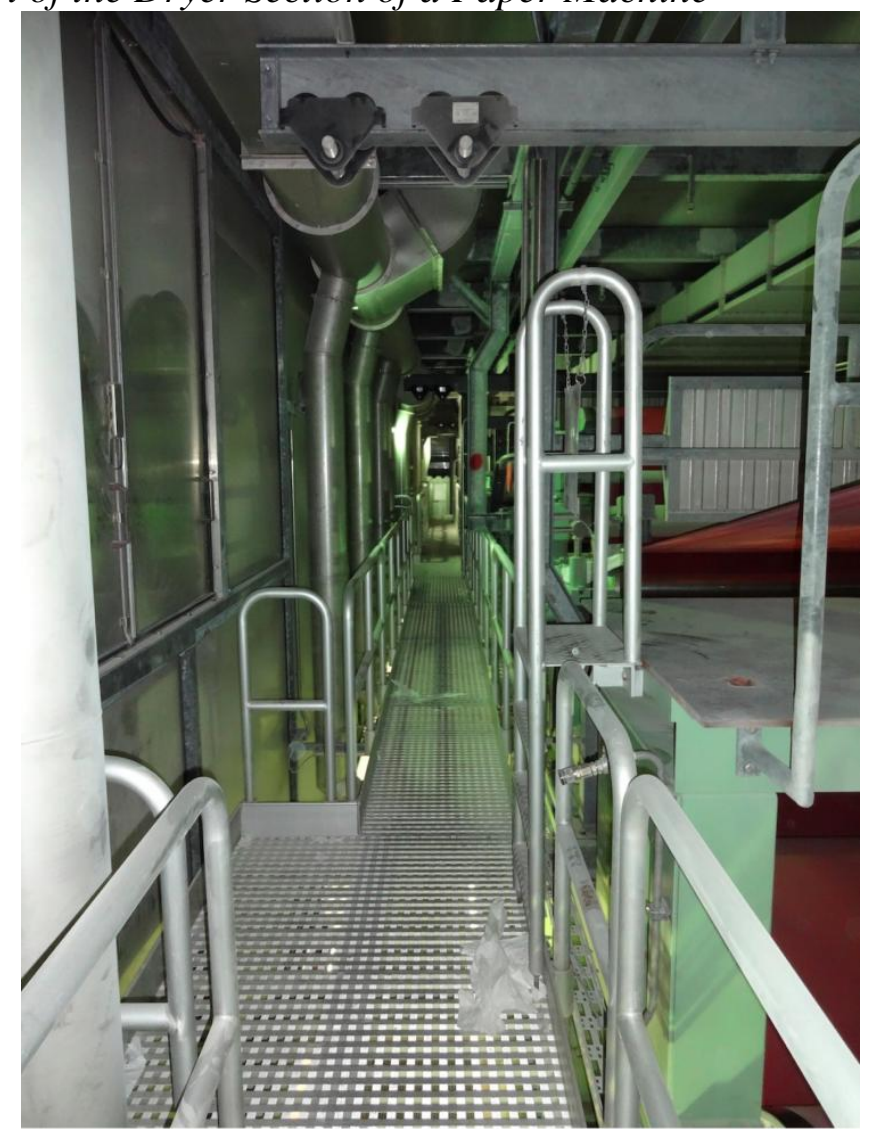


Figure 6. Time between Packets Reaching the Bridge (should be a horizontal line at 60 seconds)

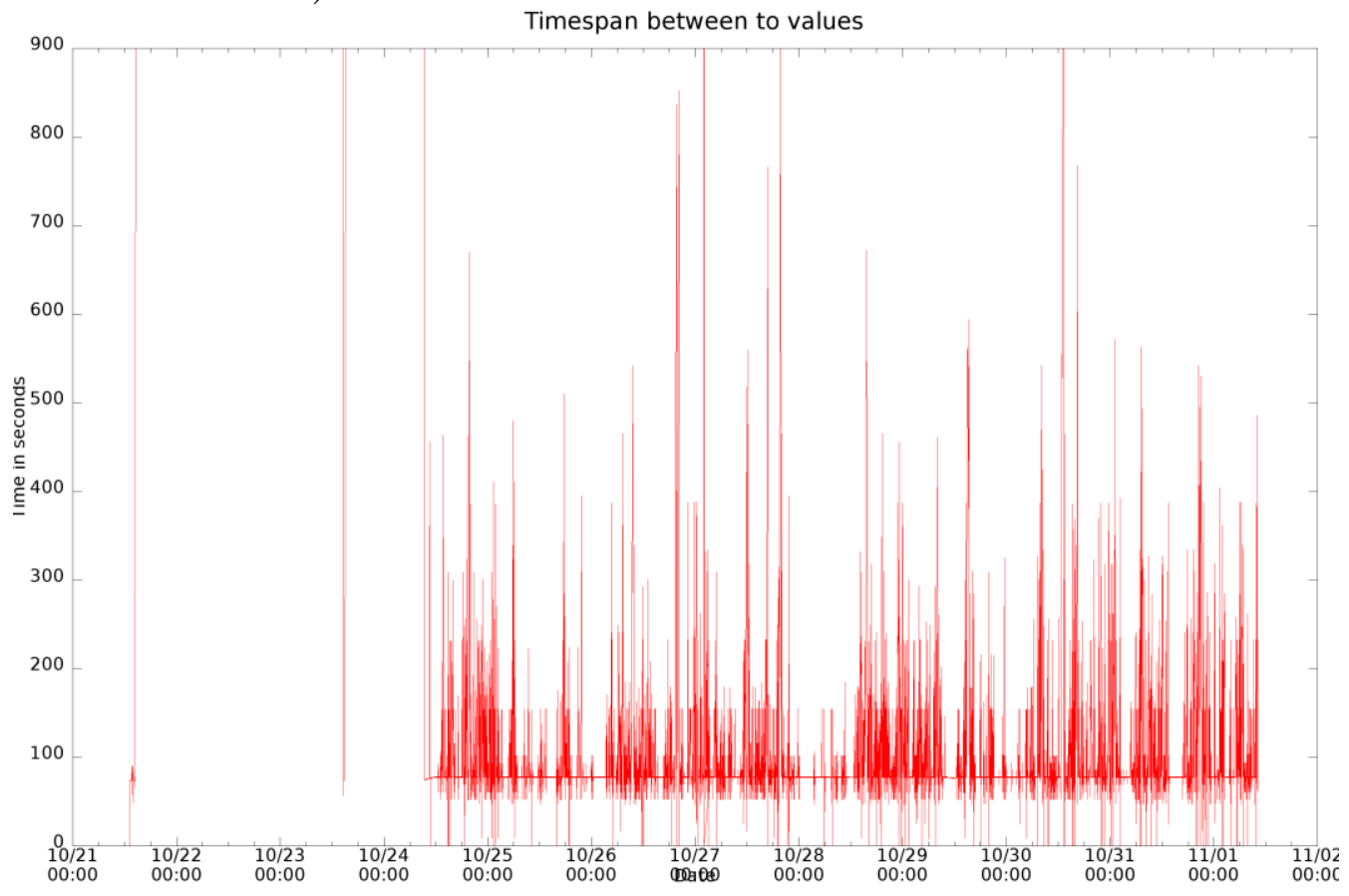

All other sensors survived the planned 4 weeks. Because of this nonpredictability of sensor lifetime, instead of the simple ad hoc solution with a single router, a mesh topology should be used in a difficult environment. The disadvantage of using every sensor node as a (candidate) router is that a router must be awake to route packets. If battery powered nodes are used, this means that the sleep times must be synchronous. In practice, this means that a maximum sleep time of some 30 seconds should be used.

The LiPo rechargeable batteries showed a performance degradation after 4 weeks at some 80 degree centigrade, so other batteries (lithium primary cells) are used now. These batteries also have about three times the capacity of the ones used in the first test run, to compensate for the shorter sleep period. In total, a lifetime of more than 8 weeks can be reached, which is more than enough for the desired application.

\section{Further Optimization Potentials}

There are concepts for using smart meters in private homes to optimize energy demand peaks. Implementing them is not a technical problem, but one of acceptance [Katz, 2011] [Zachary, 2011]. The situation in industrial production is a bit different than in private homes: To enable an efficient demand site management, it would be necessary to adapt production parameters like speed to the current energy price. From the point of view of energy producers, a direct load control would be optimal [Fadlullah, 2013]. For 
a complex system like a paper machine, this is hardly possible, unless the energy producer is the owner of the paper machine.

This is one of the reasons why most paper machines in Germany run their own power stations or cooperate with a local energy producer. In such a situation, the production parameters could be adapted dynamically to the current energy prize. To enable such optimizations, it would be necessary to make complex changes to existing paper machines, besides having flexible high performance measurement systems. In any case, these are long term perspectives.

To compensate short term demand peaks in the electrical grid, parameters like the steam mass or the air volume in the dryer could be changed for a short period of time. Flexible and precise measurement systems for temperature and humidity like the ones described in this paper are a prerequisite for this kind of optimization. Other energy intensive industries like foundries, use similar concepts and realize costs savings of 5-20\% [Bosse, 2005]

A second application of this technology is continuous machine health monitoring. New paper machines have built-in sensors for this purpose, but upgrading older machines is prohibitively costly. With wireless low power sensor networks, this is an option to reduce maintenance cost and to reduce the number of accidents.

\section{Conclusion}

This paper shows that significant cost savings can be realized by using a sensor network to measure production parameters over an extended period of time.

This kind of measurement is different from the current practice of short term, e.g. two days, measurements. Wireless data transmission and low power battery powered sensors are key to these optimizations. Using and combining data from sensor networks like the one described here are the foundation for an effective energy management.

\section{References}

Austin, Paul C. et al. 2011. Improved Energy Efficiency in Paper Making Through Reducing Dryer Steam Consumption Using Advanced Process Control. PaperCon 2011.

Bosse, M. 2005. Lastmanagement als Kontrollsystem für den Energieeinsatz und Lastspitzen von Induktionsöfen, 2005, pres

Fadlullah, Z. 2013. Research Methods and Challenges in Demand Side Management, IEEE Smart Grid, 2/2013.

GE Capital, Fall 2012, http://www.americas.gecapital.com/GECA_Document/Tech _Latest\%20Monitor.pdf 
Ghosh A. K. 2011, Fundamentals of Paper Drying - Theory and Application from Industrial Perspective in Evaporation, Condensation and Heat transfer, Intech, 2011, http://www.intechopen.com/download/get/type/pdfs/id/19429

Gislason, D. 2008. ZigBee Wireless Networking. Newnes

Katz, J. 2011. Data - The Power Behind the Smart Grid, IEEE Smart Grid, 8/2011

Küchler, S. 2013. Strompreise in Europa und Wettbewerbsfähigkeit, Green Budget Germany, http://www.foes.de/pdf/2013-01-Industriestrompreise-Wettbewerbsfae higkeit.pdf .

Ostermeier, B. 2011. Connecting Things to the Web using Programmable Low-power WiFi Modules. WoT '11 Proceedings of the Second International Workshop on Web of Things, Article No. 2, ACM

Zachary, Pascal. 2011. Saving Smart Meters From a Backlash, IEEE Spectrum, $8 / 2011$ 
